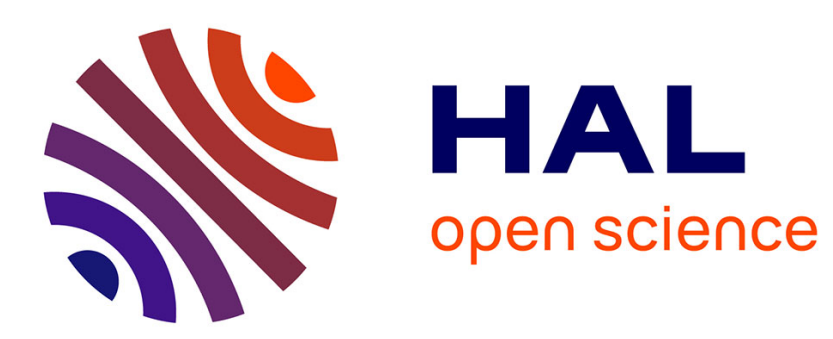

\title{
Direct sensitivity computation for the Saint-Venant equations with hydraulic jumps
}

Carole Delenne, Vincent Guinot, Bernard Cappelaere

\section{To cite this version:}

Carole Delenne, Vincent Guinot, Bernard Cappelaere. Direct sensitivity computation for the SaintVenant equations with hydraulic jumps. Comptes Rendus Mécanique, 2008, 336 (10), pp.766-771. 10.1016/j.crme.2008.09.006 . hal-01196906

\section{HAL Id: hal-01196906 https://hal.science/hal-01196906}

Submitted on 10 Sep 2015

HAL is a multi-disciplinary open access archive for the deposit and dissemination of scientific research documents, whether they are published or not. The documents may come from teaching and research institutions in France or abroad, or from public or private research centers.
L'archive ouverte pluridisciplinaire HAL, est destinée au dépôt et à la diffusion de documents scientifiques de niveau recherche, publiés ou non, émanant des établissements d'enseignement et de recherche français ou étrangers, des laboratoires publics ou privés. 


\title{
Direct sensitivity computation for the Saint-Venant equations with hydraulic jumps.
}

\author{
Carole DELENNE ${ }^{\mathrm{a}}$, Vincent GUINOT ${ }^{\mathrm{a}}$, Bernard CAPPELAERE ${ }^{\mathrm{a}}$ \\ ${ }^{\mathrm{a}}$ HydroSciences UMR 5569 (CNRS, IRD, UM1, UM2), Avenue Jeanbrau 34090 Montpellier
}

\begin{abstract}
This paper presents a new Riemann solver to solve the Saint-Venant equations in conjunction with the sensitivity problem when the solutions are discontinuous. The solver is based on the a priori assumption of two rarefaction waves. The presence of shocks is detected a posteriori and an extra sensitivity term in the form of a Dirac source term is accounted for in the sensitivity balance equations. To cite this article: C. Delenne, V. Guinot, B. Cappelaere, C. R. Mecanique?? (2008).
\end{abstract}

Résumé

Calcul direct de sensibilité pour les équations de Saint-Venant avec ressauts hydrauliques. On propose ici un solveur de Riemann pour résoudre les équations de sensibilité conjointement à la projection sur une dimension des équations de Saint-Venant dans le cas de solutions discontinues. Le solveur est basé sur la supposition a priori de deux ondes de raréfaction. La présence de chocs est détectée a posteriori et un terme supplémentaire, sous la forme d'un terme source de Dirac, est introduit dans l'équilibre des équations de sensibilité. Pour citer cet article : C. Delenne, V. Guinot, B. Cappelaere, C. R. Mecanique?? (2008).

Key words: Computational fluid mechanics; Sensitivity ; Hyperbolic conservation laws ; shocks

Mots-clés : Mécanique des fluides numérique; Sensibilités; Lois de conservation hyperboliques; Chocs

\section{Version française abrégée}

On cherche à résoudre les équations de sensibilité conjointement à la projection sur une dimension des équations de Saint Venant dans le cas de solutions discontinues. Dans ce cas, en effet, les équations en sensibilité ne peuvent pas être obtenues par une simple dérivation des équations hydrodynamiques de base et un terme source de Dirac apparaît au niveau des chocs. On propose ici une méthode numérique

Email addresses: delenne@msem.univ-montp2.fr (Carole DELENNE), guinot@msem.univ-montp2.fr (Vincent GUINOT), cappelaere@msem.univ-montp2.fr (Bernard CAPPELAERE). 
de calcul aux volumes finis, dont le principe est le suivant : (i) définir le problème de Riemann entre deux cellules $i$ et $j$ (issues d'une discrétisation de l'espace) avec des états gauche et droit définis par ces deux cellules respectivement; (ii) déterminer les valeurs de la variable d'écoulement et/ou des flux dans les régions d'états constants en utilisant les invariants de Riemann, (iii) déterminer les vitesses de propagation des différentes ondes et la localisation de discontinuité par rapport à ces ondes; (iv) calculer les flux nécessaires pour équilibrer l'équation entre les cellules $i$ et $j$ grâce à la valeur de la variable d'écoulement au niveau de la discontinuité initiale. La solution est alors calculée pour différents pas de temps en utilisant un schéma de discrétisation explicite.

The Riemann problem of the Saint-Venant and sensitivity equations is first recalled and then the application of the proposed solver is detailed.

\section{The Riemann problem}

The one-dimensional projection of the Saint-Venant equations is a $3 \times 3$ Hyperbolic System of Conservation Laws (HSCL), which can be written in vector form as :

$$
\left.\begin{array}{rl}
\frac{\partial \mathbf{U}}{\partial t}+\frac{\partial \mathbf{F}(\mathbf{U}, \phi)}{\partial x} & = \\
\mathbf{U}(x, 0) & =\mathbf{U}_{0}(x, \phi) \\
\mathbf{U}\left(x_{b}, t\right) & =\mathbf{U}_{b}(t, \phi)
\end{array}\right\} \text { with } \mathbf{U}=\left(\begin{array}{c}
h \\
q \\
r
\end{array}\right), \mathbf{F}=\left(\begin{array}{c}
q \\
q^{2} / h+g h^{2} / 2 \\
q r / h
\end{array}\right)
$$

with $\mathbf{U}$ : the conserved variable; $\mathbf{F}$ : the flux function $; \phi$ : a parameter on which the flux depends; $g$ : the gravitational acceleration; $h$ : the water depth; $q$ (resp. $r$ ) : the unit discharge in the $x$ (resp. $y$ ) direction; $u=q / h$ (resp. $v=r / h$ ) : the flow velocity in the $x$ (resp. $y$ ) direction. The superscripts $b$ and 0 indicate the domain boundary abscissa and the initial condition respectively.

Differentiating the governing equation 1 with respect to the parameter $\phi$ leads to the equation for the sensitivity $\mathbf{s}=(\eta, \theta, \rho)$ of $\mathbf{U}$ to $\phi$ :

$$
\frac{\partial \mathbf{s}}{\partial t}+\frac{\partial}{\partial x}(\mathbf{A s})=-\frac{\partial}{\partial x}\left(\frac{\partial \mathbf{F}}{\partial \phi}\right)
$$

with $\mathbf{A}=\partial \mathbf{F} / \partial \mathbf{U}$

However, this derivation is correct only under the assumption of a continuous and differentiable solution $\mathbf{U}[7]$. In the presence of a discontinuity, the so-called Rankin-Hugoniot conditions (or jump relationships) must be used :

$$
\mathbf{F}_{\mathbf{L}}-\mathbf{F}_{\mathbf{R}}=\left(\mathbf{U}_{\mathbf{L}}-\mathbf{U}_{\mathbf{R}}\right) c_{s}
$$

where $c_{s}$ is the discontinuity speed, and where the index $\mathrm{L}$ and $\mathrm{R}$ denote the left and right states across the discontinuity. Moreover, since $\mathbf{U}$ and $\mathbf{s}$ are independent variables, the sensitivities $\mathbf{S}_{\mathbf{L}}$ and $\mathbf{s}_{\mathbf{R}}$ on the left and right-hand side of the discontinuity are independent from $\mathbf{U}_{\mathbf{L}}$ and $\mathbf{U}_{\mathbf{R}}$. Consequently, the jump relationship for the sensitivity is much more complex than that for the flow variable ([1], [6]) and implies a specific source term $\mathbf{R}$, in a form of a Dirac function, which takes effect only at the discontinuity :

$$
\mathbf{H}_{\mathbf{L}}-\mathbf{H}_{\mathbf{R}}+\mathbf{R}=\left(\mathbf{s}_{\mathbf{L}}-\mathbf{S}_{\mathbf{R}}\right) c_{s}
$$

with $\mathbf{s}$ the conserved variable and $\mathbf{H}=\mathbf{A s}$ the flux function for sensitivity. Then,

$$
\mathbf{R}=\left(\mathbf{s}_{\mathbf{L}}-\mathbf{s}_{\mathbf{R}}\right) c_{s}-\mathbf{H}_{\mathbf{L}}+\mathbf{H}_{\mathbf{R}}=\left(\mathbf{A}_{\mathbf{R}}-c_{s} \mathbf{I}\right) \mathbf{s}_{\mathbf{R}}-\left(\mathbf{A}_{\mathbf{L}}-c_{s} \mathbf{I}\right) \mathbf{S}_{\mathbf{L}}
$$


which can be written as :

$$
\mathbf{R}=\Delta\left[\left(\mathbf{A}-c_{s} \mathbf{I}\right) \mathbf{s}\right]
$$

The source term $\mathbf{R}$ is non zero only when there is a shock. Indeed, when the discontinuity is a contact one, $c_{s}$ is an eigenvalue of the matrix $\mathbf{A}$ and $\left(\mathbf{A}_{\mathbf{R}, \mathbf{L}}-c_{s} \mathbf{I}\right)=0$.

Because this Jacobian matrix A depends on the solution $\mathbf{U}$, the Riemann problem of the sensitivity cannot be considered independently from the one of the flow variable. We thus consider the following initial-value problem :

$$
\left.\begin{array}{cc}
\frac{\partial \mathbf{U}}{\partial t}+\frac{\partial \mathbf{F}}{\partial x}= & 0 \\
\frac{\partial \mathbf{s}}{\partial t}+\frac{\partial \mathbf{H}}{\partial x}= & \Delta\left[\left(\mathbf{A}-c_{s} \mathbf{I}\right) \mathbf{s}\right] \\
(\mathbf{U}, \mathbf{s})(x, 0)= \begin{cases}\left(\mathbf{U}_{\mathbf{L}}, \mathbf{s}_{\mathbf{L}}\right) & \text { for } x<0 \\
\left(\mathbf{U}_{\mathbf{R}}, \mathbf{s}_{\mathbf{R}}\right) & \text { for } x>0\end{cases}
\end{array}\right\}
$$

which is a $3 \times 3 \mathrm{HSCL}$ with the following eigenvalues :

$$
\left(\lambda^{(1)}, \lambda^{(2)}, \lambda^{(3)}\right)=(u-c, u, u+c)
$$

The general solution of the Riemann problem is made of three waves separating two internal regions of constant state. In the exact solution of the Riemann problem, the second wave (with celerity $\lambda^{(2)}=u$ ) is a contact discontinuity, while the first and third waves may be of any type, depending on $\mathbf{U}_{\mathbf{L}}$ and $\mathbf{U}_{\mathbf{R}}$. Although not strictly valid across a shock, the Riemann invariants may be used to approximate the jump relationships (e.g. [8], [10], [4], [3], [9]). Then, the nature of the waves in the Riemann problem may be guessed a priori without a posteriori verification and the resulting system of algebraic equations may be solved to determine directly the solution in the intermediate regions of constant state. The proposed approximate-state Riemann solver uses the assumption that the eigenvalues (5) are the celerities of three rarefaction waves. In what follows, we assess the sensitivity of the solution to the initial value of the left or right state of $\mathbf{U}$.

\section{The Approximate-state Riemann solver}

\subsection{Discretization}

The solution will be advanced in time using the following discretization of (4) :

$$
\begin{gathered}
\mathbf{U}_{i}^{n+1}=\mathbf{U}_{i}^{n}+\frac{\Delta t}{\Delta x_{i}}\left(\mathbf{F}_{i-1 / 2}^{n+1 / 2}-\mathbf{F}_{i+1 / 2}^{n+1 / 2}\right) \\
\mathbf{s}_{i}^{n+1}=\mathbf{s}_{i}^{n}+\frac{\Delta t}{\Delta x_{i}}\left(\mathbf{H}_{i-1 / 2}^{n+1 / 2}-\mathbf{H}_{i+1 / 2}^{n+1 / 2}+\mathbf{R}_{i-1 / 2, i}^{n+1 / 2}+\mathbf{R}_{i+1 / 2, i}^{n+1 / 2}\right)
\end{gathered}
$$

where $\mathbf{U}_{i}^{n}$ and $\mathbf{s}_{i}^{n}$ are the average values of $\mathbf{U}$ and $\mathbf{s}$ over the cell $i$ at the time $n ; \mathbf{F}_{i-1 / 2}^{n+1 / 2}$ and $\mathbf{H}_{i-1 / 2}^{n+1 / 2}$ are the average values of the fluxes $\mathbf{F}$ and $\mathbf{H}$ at the interface $i-1 / 2$ between the cells $i-1$ and $i$ over the time interval $\left[t^{n}, t^{n+1}\right] ; \mathbf{R}_{i-1 / 2, i}^{n+1 / 2}$ and $\mathbf{R}_{i+1 / 2, i}^{n+1 / 2}$ represent the contributions of the source terms possibly generated by shocks propagating respectively from the interfaces $i+1 / 2$ and $i-1 / 2$ into the cell $i$; $\Delta t$ is the computational time step and $\Delta x_{i}$ is the width of the cell $i$.

For each interface between two cells $i$ and $j$ (issued from a spatial discretization), a Riemann problem is defined with left and right states taken from these cells. Then, the proposed solver uses the classical HLL approach to compute the solution in the continuous case and a specific treatment of the shocks. 


\subsection{Continuous case}

The Riemann invariants for (4) are defined as [5] :

$$
\begin{cases}\mathrm{d}(u-2 c)=0 & \text { for } \frac{\mathrm{d} x}{\mathrm{~d} t}=u-c \\ \mathrm{~d} v=0 & \text { for } \frac{\mathrm{d} x}{\mathrm{~d} t}=u \\ \mathrm{~d}(u+2 c)=0 & \text { for } \frac{\mathrm{d} x}{\mathrm{~d} t}=u+c\end{cases}
$$

and therefore, noting $\chi, \nu, \omega$ the sensitivities of $c, u, v$ with respect to the parameter $\phi$ :

$$
\begin{cases}\mathrm{d}(\nu-2 \chi)=0 & \text { for } \frac{\mathrm{d} x}{\mathrm{~d} t}=u-c \\ \mathrm{~d} \omega=0 & \text { for } \frac{\mathrm{d} x}{\mathrm{~d} t}=u \\ \mathrm{~d}(\nu+2 \chi)=0 & \text { for } \frac{\mathrm{d} x}{\mathrm{~d} t}=u+c\end{cases}
$$

In the regions of constant state (see figure 1), using the approximate expressions (8) and (9) yields :

$$
\begin{aligned}
& \left\{\begin{array}{l}
c_{*, 1}=c_{*, 2}=\frac{1}{2}\left(c_{L}+c_{R}\right)+\frac{1}{4}\left(u_{L}-u_{R}\right) \\
u_{*, 1}=u_{*, 2}=\frac{1}{2}\left(u_{L}+u_{R}\right)+c_{L}-c_{R} \\
v_{*, 1}=v_{L} \\
v_{*, 2}=v_{R}
\end{array}\right. \\
& \begin{cases}\chi_{*, 1}=\chi_{*, 2}=\frac{1}{2}\left(\chi_{L}+\chi_{R}\right)+\frac{1}{4}\left(\nu_{L}-\nu_{R}\right) \\
\nu_{*, 1}=\nu_{*, 2}=\frac{1}{2}\left(\nu_{L}+\nu_{R}\right)+\chi_{L}-\chi_{R} \\
\omega_{*, 1}=\omega_{L} \\
\omega_{*, 2}=\omega_{R}\end{cases}
\end{aligned}
$$

where the subscript ${ }^{*}, 1$ and ${ }^{*}, 2$ denote the values of the variables in the intermediate regions of constant state on the left and right-hand sides of the contact discontinuity, respectively. The flux $\mathbf{H}$ in the regions of constant state is then determined uniquely from (11) :

$$
\mathbf{H}_{*, p}=\left[\begin{array}{c}
\theta_{*, p} \\
\left(c_{*, p}^{2}-u_{*, p}^{2}\right) \eta_{*, p}+2 u_{*, p} \theta_{*, p} \\
-u_{*, p} \nu_{*, p} \eta_{*, p}+\nu_{*, p} \theta_{*, p}+u_{*, p} \rho_{*, p}
\end{array}\right] p=1,2
$$

Using the fact that $h=c^{2} / g, q=h u$ and $r=h v$, yields the sensitivity $\mathbf{s}_{*, p}$ :

$$
\left(\begin{array}{c}
\eta \\
\theta \\
\rho
\end{array}\right)_{*, p}=\left(\begin{array}{c}
2 c \chi / g \\
\eta u+h \nu \\
\eta v+h \omega
\end{array}\right)_{*, p}
$$




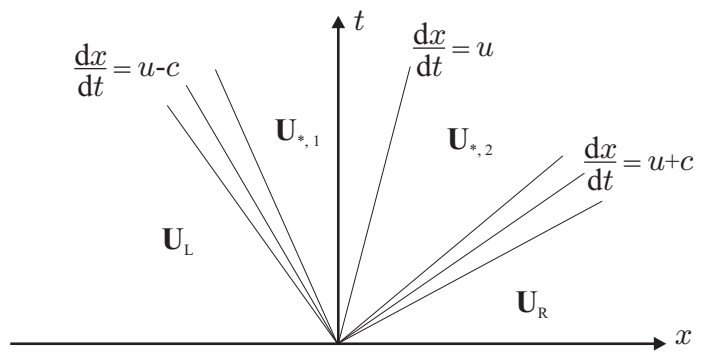

Fig. 1. Scheme of the different regions for the Saint-Venant equations solution

\subsection{Shock treatment}

A shock appears on the first or third wave (and consequently a source term $\mathbf{R}$ ) when either $u_{L}-c_{L}>$ $u_{R}-c_{R}$ or $u_{L}+c_{L}>u_{R}+c_{R}$. The shock speed is estimated using one of the following relationships (with the superscript $L$ and 1 or $R$ and 2 if the shock is on the first or third wave respectively) :

$$
\begin{gathered}
c_{s}=\frac{q_{\{L, R\}}-q_{*,\{1,2\}}}{h_{\{L, R\}}-h_{*,\{1,2\}}} \\
c_{s}=\frac{\left(q^{2} / h+g h^{2} / 2\right)_{\{L, R\}}-\left(q^{2} / h+g h^{2} / 2\right)_{*,\{1,2\}}}{q_{\{L, R\}}-q_{*,\{1,2\}}}
\end{gathered}
$$

or $\left(u_{\{L, R\}}+u_{*,\{1,2\}}\right) / 2$ if the previous two denominators are null.

If the shock speed in negative, the corresponding wave travels from the interface $i-1 / 2$ into the cell $i-1$ and does not yield any source term in the cell $i$. In contrast, if the speed is positive, the wave travels into the cell $i$ and contributes to the source term $\mathbf{R}_{i-1 / 2, i}^{n+1 / 2}$ by a quantity given by equation (3).

\subsection{Fluxes at the interface}

At the end of the process, the fluxes can be computed at the interface using :

$$
\begin{aligned}
\mathbf{F}_{i-1 / 2}^{n+1 / 2} & =\mathbf{F}\left(\mathbf{U}_{i-1 / 2}^{n+1 / 2}\right) \\
\mathbf{A}_{i-1 / 2}^{n+1 / 2} & =\mathbf{A}\left(\mathbf{U}_{i-1 / 2}^{n+1 / 2}\right) \\
\mathbf{H}_{i-1 / 2}^{n+1 / 2} & =\mathbf{A}_{i-1 / 2}^{n+1 / 2} \mathbf{s}_{i-1 / 2}^{n+1 / 2}
\end{aligned}
$$

The whole process is then repeated in time using 6 and 7 .

\subsection{Example}

The figure 2 shows the calculation of the water height and the sensitivity to the initial left water height value $h_{L}$, in the case of the dam-break problem. 


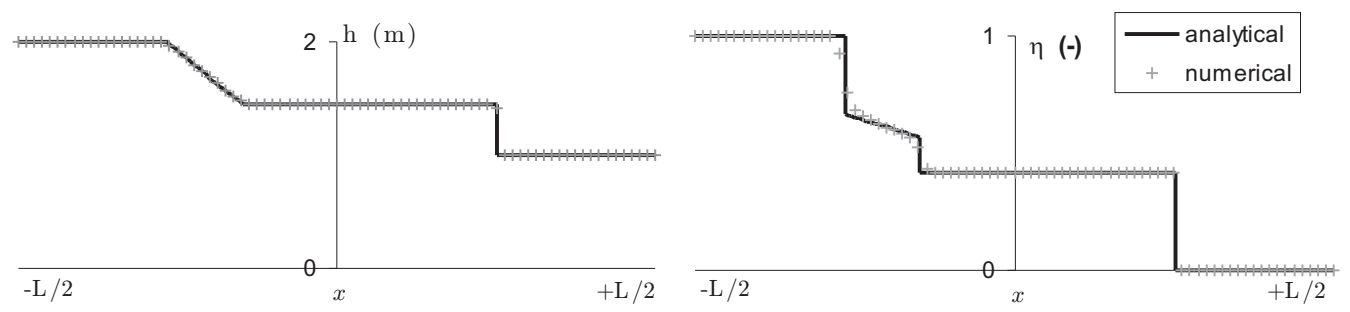

FIG. 2. Water height $h$ and sensitivity $\eta$ to the initial left water height value $h_{L}$

\section{Conclusion}

The proposed approximate state Riemann solver has been applied here to solve the shallow water and sensitivity equations when shocks are present in the solution. It will be generalized to other HSCL and other case study in forthcoming publications.

\section{Références}

[1] Bardos, C., Pironneau, O., 2002, A formalism for the differentiation of conservation laws. C.R Acad. Sci. Paris, Ser. I 335, p.839-845.

[2] Dukowicz, J.K., 1985, A general, non-iterative Riemann solver for Godunov's method. Journal of Computational Physics $61,119-137$.

[3] Guinot, V., 2000, Riemann solvers for water hammer simulations by Godunov method. International Journal for Numerical Methods in Engineering 49, 851-870.

[4] Guinot, V., Godunov-type schemes. An introduction for engineers. Elsevier.

[5] Guinot, V., 2006, Ondes en mécanique des fluides. Modélisation et simulation numérique. Hermes Publishing (in French).

[6] Guinot, V., Leménager, M., Cappelaere, B., 2007, Sensitivity equations for hyperbolic conservation law-based flow models. Advances in Water Resources, 30 : 1943-1961.

[7] Gunzburger, M. D., 1999, Sensitivities, adjoints and flow optimization, International Journal for Numerical Methods in Fluids, 31 : 53-78.

[8] Lax, PD., 1957, Hyperbolic systems of conservation laws. Communications in Pure and Applied Mathematics, 10, 537-566.

[9] Lhomme, J., Guinot, V., in press, A general, approximate-state Riemann solver for hyperbolic systems of conservation laws with source terms. International Journal for Numerical Methods in Fluids.

[10] Toro, EF., 1997, Riemann solvers and numerical methods for fluid dynamics. Springer. 